\title{
Declining Rate of Operative Vaginal Deliveries in Nigeria
}

\author{
Okechukwu Bonaventure Anozie ${ }^{1 *}$, Lawani Lucky Osaheni' ${ }^{1}$, Fidelis A. Onu${ }^{1}$, \\ Robinson Chukwudi Onoh', Emeka Onwe Ogah², Justus N. Eze ${ }^{3}$, \\ Johnbosco E. Mamah', Obiora G. Asiegbu' ${ }^{1}$, Rita O. Anozie ${ }^{4}$
}

${ }^{1}$ Department of Obstetrics \& Gynaecology, Federal Teaching Hospital Abakaliki, Abakaliki, Nigeria

${ }^{2}$ Department of Paediatrics, Federal Teaching Hospital Abakaliki, Abakaliki, Nigeria

${ }^{3}$ Department of Obstetrics \& Gynaecology, Ebonyi State University Abakaliki, Nigeria

${ }^{4}$ Department of Radiology, Federal Teaching Hospital Abakaliki, Abakaliki, Nigeria

Email: *okeyanoziey2k@yahoo.com

How to cite this paper: Anozie, O.B., Osaheni, L.L., Onu, F.A., Onoh, R.C., Ogah, E.O., Eze, J.N., Mamah, J.E., Asiegbu, O.G. and Anozie, R.O. (2018) Declining Rate of Operative Vaginal Deliveries in Nigeria. Open Journal of Obstetrics and Gynecology, 8, 175-184.

https://doi.org/10.4236/ojog.2018.83021

Received: November 23, 2017

Accepted: March 10, 2018

Published: March 13, 2018

Copyright ( 2018 by authors and Scientific Research Publishing Inc. This work is licensed under the Creative Commons Attribution International License (CC BY 4.0).

http://creativecommons.org/licenses/by/4.0/

(c) (i) Open Access

\begin{abstract}
Background: The application of invasive obstetric procedures has an end point of reducing the Caesarean section rate. The declining rate of use of these procedures is one of the reasons for increasing Caesarean section rates in our environment. Objective: The aim of the study was to determine the practice of operative vaginal deliveries among obstetricians practicing in Nigeria and to evaluate the reasons for non-use of these procedures. Methodology: It was a questionnaire based study. The questionnaires were administered to practitioners of Obstetrics in the various centres in Nigeria. Data was collated and analyzed with Epi-Info statistical software version 7.0 (Center for Disease Control and Prevention, USA), and conclusions were drawn by means of descriptive statistics. Results: A total of 1200 questionnaire were distributed but 1104 were returned and used for analysis. This gave a response rate of $92 \%$. The age distribution of the respondents showed that the 20 - 30 year age group had the least number of respondents $22(2 \%)$ while 41 - 50 age group had the highest number of respondents $486(4 \%)$. The majority of the respondents were males 839 (76\%). In terms of duration of practice, 449 (40.7\%) of the respondents had more than 6 years duration of practice while 256 (23.2) had practiced for less than 3 years. Tertiary centres had highest number of respondents $71.8 \%$. The distribution of the respondents according to the geopolitical zones in Nigeria are; South-East (57.6\%), South-South (19.6\%), South West (11.4\%), North-West (4.9\%), North-East (3.8\%), North-Central (2.7\%). The practice of these procedures among respondents were: External cephalic version (68.0\%), Symphysiotomy (41.7), Forceps delivery (68.8\%), Destructive delivery (60.1\%), Vaginal breech delivery (85.5\%), Vacuum extraction (84.8\%). Reasons for the non-use included: Risk of perinatal/maternal mor-
\end{abstract}


bidity and mortality greater than benefit (25.7\%), Lack of equipment (22.4\%), Lack of skills (16.6\%), Decline by patients (6.5\%), Not in the departmental protocol (26.2\%), Not evidence based (34.6\%), Patient preferred Caesarean section (5.6\%), Outdated (32.6\%), fear of litigation (32.7\%). The mean rate of caesarean section according to rates reported from different centres was $25.2 \%$ while the individual centre rates ranged from $2 \%$ to as high as $51 \%$. Conclusion: There is a decline in the practice of operative obstetric procedures among obstetricians practicing in Nigeria. There is an urgent need to reverse this trend by increased training and re-training of manpower, provision of necessary equipment, more research to provide supportive evidence of need and inclusion in protocols.

\section{Keywords}

Invasive Obstetric Procedures, Decline, Nigeria

\section{Introduction}

Operative vaginal delivery is an age-long obstetric practice used to expedite delivery or avert recourse to caesarean delivery [1]. It is a vital component of basic emergency obstetric care worldwide and remains an integral part of the obstetrician's duties. It may take the form of instrumental deliveries, employing obstetric forceps and vacuum extractor to shorten the second stage of labour or operative procedures like symphysiotomy or destructive operations performed to achieve vaginal delivery in dystocia with or without a living fetus [2]. The relevance of these procedures cannot be over emphasized in a resource constraint setting like ours where poverty, ignorance and obnoxious cultural practices have led to a very high morbid aversion for caesarean section among obstetric women [3]. It is not unusual for women with obvious indication for caesarean section to patronize quacks and traditional birth attendants in a bid to achieve vaginal delivery, which sometimes results in avoidable maternal and perinatal morbidity and mortality [4]. Matter-of-fact, in some well selected patients, an indication for caesarean section might be amenable to operative vaginal delivery especially when the skill is available and/or the equipment is functional, a recourse to such alternative mode of delivery will reduce morbidity, cost and ultimately the increasing caesarean section rates prevalent in our obstetric practice [5].

There has been a declining trend in the use of operative vaginal deliveries in contemporary obstetric practice. Much of this decline can be attributed to fears of complications, litigation and lack of skills [6] [7]. Vacuum and forceps extraction is still fairly common although vacuum extraction is by far the more common procedure performed in developing countries [7] [8]. By the year 2000, forceps delivery had decreased to under half with much of the decline attributed to increasing preference for vacuum extraction or caesarean section when difficult vaginal delivery is anticipated [2] [9] [10] [11]. Although destructive opera- 
tions and symphysiotomy are obsolete in developed countries, they remain relevant and lifesaving obstetric procedures in developing countries where obstetric practice is still rudimentary and the high aversion for caesarean section in this setting makes these procedures indispensable [12] [13]. One major reason for such high aversion for caesarean section there is failure to achieve vaginal delivery is often considered, albeit wrong, a reproductive failure of the parturient woman [14].

Recent trends show that the cesarean delivery rate has increased over the past decade (30.3\% in the USA in 2005 and $21.3 \%$ in England in 2001) while the operative vaginal delivery rate has decreased globally, although both rates vary significantly around the world [13] [15] [16] [17]. Fears of potential neonatal and maternal safety have been the primary drivers of these trends, also few obstetricians who are proficient in using forceps are able to meet up with the ever increasing number of residents [18]. Professional liability due to birth injuries associated with not doing a timely cesarean section and complicated operative deliveries are common reasons for obstetric malpractice suits [19] [20] [21]. An operative vaginal delivery rate of $3.5 \%$ was reported in the United States as against a caesarean section rate of $32.8 \%$ [22]. Similar trend was also reported from similar studies elsewhere [23] [24] [25]. Both the American College and the Royal College of Obstetricians and Gynecologists continue to support the use of both vacuum and forceps and strongly encourage residency programs to incorporate the teaching of these skills into their curricula [26] [27]. In view of the decline of this practice in modern obstetrics, there is a need for continued training and retraining, and proper patient selection in order to reduce the incidence of complications and litigation that may follow operative vaginal deliveries.

This study aims to determine the determinants and deterrents to use of operative vaginal delivery procedures among obstetricians practicing in Nigeria and highlight their benefits in our obstetric practice where high maternal, perinatal morbidity and mortality following caesarean section remains an issue.

\section{Material and Methods}

\section{Background}

The Society of Gynaecology and Obstetrics of Nigeria (SOGON) is the umbrella body to which registered Obstetricians and Gynaecologists in Nigeria belong. It was established in 1965 to regulate Obstetrics and Gynaecological practice in Nigeria. The annual general meeting and scientific conference of the society of Gynaecology and Obstetrics of Nigeria is an annual event that brings together the Obstetricians and Gynaecologists practicing in Nigeria. It is usually well attended where issues affecting the society are usually discussed. Members also showcase breakthroughs in their practices and present scientific articles which are usually published in the society's journal. This occasion provided an ideal avenue for a study of this nature. This study was a questionnaire-based cross-sectional study of Obstetricians and Gynecologists that attended the 48th Annual General Meeting and Scientific Conference of the Society of Gynaecolo- 
gy and Obstetrics of Nigeria (SOGON) held in Asaba, Delta State, Southern Nigeria in November, 2014. The SOGON conference is an annual event usually held in the last week of the month of November every year.

\section{Study design}

This was a cross-sectional questionnaire based study; pre-tested semi-structured questionnaires were administered to obstetricians during the Society of Gynaecology and Obstetricians (SOGON) scientific conference in Asaba, Delta State of Nigeria. The questionnaire was pretested on 40 doctors in the department of obstetrics and Gynaecology of the Federal Teaching Hospital, Abakaliki. These doctors had indicated their intention not to attend the conference and as such didn't participate in the final survey. The pilot study revealed areas of confusion and these were corrected in the final draft used for data collection. A total of 1200 questionnaires were administered to Obstetricians and Gynecologists and trainees that consented to participate in the study but 1104 questionnaires were correctly filled and returned, this gave a response rate of $92 \%$. Information were obtained on age and length of practice, geo-political zone of practice, invasive procedures performed, reasons for performing or non performing of the procedures, Caesarean section rate in place of practice and what could be done to encourage the practice of operative vaginal deliveries. Ethical approval was obtained from the ethics committee of Federal Teaching Hospital Abakaliki, before embarking on this study.

\section{Data analysis}

Data was collated and analyzed with Epi-Info statistical software version 7.0 (Center for Disease Control and Prevention, USA), and conclusions were drawn by means of descriptive statistics.

\section{Limitation}

A major limitation of this study is problem of recall bias from the respondents. Also not all the obstetricians practicing in Nigeria attended this conference and as such the findings from this study may not truly represent the view of all the obstetricians in Nigeria.

\section{Results}

A total of 1200 questionnaires were distributed and 1104 were correctly filled, returned and used for analysis. This gave a response rate of $92 \%$.

Table 1 shows the sociodemographic characteristics of the respondents. The age distribution of the respondents showed that the 20 - 30 year age group had the least number of respondents $22(2 \%)$ while 41 - 50 age group had the highest number of respondents $486(4 \%)$. The majority of the respondents were males $839(76 \%)$ while the females made up $24 \%$. In terms of duration of practice, 449 $(40.7 \%)$ of the respondents had more than 6 years duration of practice while 256 (23.2) had practiced for less than 3 years. Tertiary centres had highest number of respondents $71.8 \%$ while $10 \%$ of them were in private practice.

Table 2 shows the distribution of the respondents according to the geopolitical zones in the country. South East 636 (57.6\%), South South 216 (19.6\%), 
South West 126 (11.4\%), North West 54 (4.9\%), North East 42 (3.8\%), North Central 30 (2.7\%).

Table 3 shows the distribution of practice of operative vaginal deliveries among the respondents. External cephalic version (68.0\%), symphysiotomy (41.7\%), forceps delivery (68.8\%), destructive delivery $(60.1 \%)$, vaginal breech delivery (85.5\%), Vacuum extraction $(84.8 \%)$.

Table 4 shows the reasons for non-use of some operative vaginal deliveries among the respondents. Risk of perinatal and maternal morbidity and mortality greater than benefit (25.7\%), lack of equipment (22.4\%), lack of skills (16.6\%), decline by patients $(6.5 \%)$, not in departmental protocol $(26.2 \%)$, not evidence based $(34.6 \%)$, patient preferred caesarean section (5.6\%), outdated (32.6\%), fear of litigation following complications $32.7 \%$.

Table 1. Sociodemographic characteristics.

\begin{tabular}{ccc}
\hline Variables & Frequency & Percentage (\%) \\
\hline Age (years) & 22 & 2 \\
$20-30$ & 464 & 42 \\
$30-40$ & 486 & 44 \\
$41-50$ & 88 & 8 \\
$51-60$ & 44 & 4 \\
$>60$ & & 76 \\
Sex & 839 & 24 \\
Male & 265 & \\
Female & & 23.2 \\
of practice (years) & 256 & 36.1 \\
$1-3$ & 399 & 40.7 \\
$4-6$ & 449 & 10.2 \\
$>6$ & & 71.8 \\
Duration & 793 & 10.2 \\
Tertiary & 201 & \\
Secondary & 110 & \\
Private & & \\
\hline
\end{tabular}

Table 2. Distribution of respondents according to geopolitical zones in Nigeria.

\begin{tabular}{ccc}
\hline Geopolitical zone & Frequency & Percentage (\%) \\
\hline South east & 636 & 57.6 \\
South south & 216 & 19.6 \\
South west & 126 & 11.4 \\
North west & 54 & 4.9 \\
North east & 42 & 3.8 \\
North central & 30 & 2.7 \\
Total & 1104 & 100
\end{tabular}


Table 3. Practice of operative vaginal deliveries among respondents.

\begin{tabular}{ccc}
\hline Operative procedure & Frequency & Percentage (\%) \\
\hline External cephalic version & 751 & 68.0 \\
Symphysiotomy & 460 & 41.7 \\
Forceps delivery & 759 & 68.8 \\
Destructive surgery & 663 & 60.1 \\
Vaginal breech delivery & 944 & 85.5 \\
Vacuum extraction & 936 & 84.8 \\
\hline
\end{tabular}

Table 4. Reasons for non-regular use of obstetric vaginal deliveries.

\begin{tabular}{ccc}
\hline Reason & Frequency & Percentage (\%) \\
\hline Lack of equipment & 247 & 22.4 \\
Lack of skills & 183 & 16.6 \\
Decline by patients & 72 & 6.5 \\
Not evidence based & 382 & 34.6 \\
Outdated & 360 & 32.6 \\
Not recognized by the & 290 & 26.2 \\
departmental protocol & 62 & 5.6 \\
Patient prefers caesarean section & 284 & 25.7 \\
Risks outweigh benefits & 361 & 32.7 \\
Fear of litigation & & \\
\hline
\end{tabular}

\section{Discussion}

The age distribution of the respondents showed that 20 - 30 year age group had the least number of respondents $22(2 \%)$ while $41-50$ age group had the highest number, $486(4 \%)$. The majority of the respondents were males $839(76 \%)$ while the females made up $24 \%$. In terms of duration of practice, $449(40.7 \%)$ of the respondents had more than 6 years duration of practice while 256 (23.2) had practiced for less than 3 years. Tertiary centres had highest number of respondents $71.8 \%$. This can easily be explained by the fact that in Nigeria, government is the highest employer of labour and majority of the tertiary health centres in Nigeria are government owned.

The South East and South South geo-political regions respectively had the highest number of respondents $636(57.6 \%)$ and $216(19.6 \%)$. This may be as a result of proximity to the venue of the conference, Asaba. The Northwest, Northeast and North central regions had low representation because they are worst hit by the problem of terrorism and this has led to brain drain of alarming proportion [28].

Recent trends have shown increasingly predominance of vacuum extraction over forceps delivery [29] [30] [31] [32]. This was reflected in this study where $68.03 \%$ reported practicing forceps delivery as against $84.8 \%$ who report use of 
vacuum extraction. Interests were not comparable in symphysiotomy $(41.67 \%)$ and destructive delivery (60.07\%). Although symphysiotomy and destructive operations are potentially life-saving procedures but often reluctantly used in the western world where it is viewed as an outdated or second class obstetric intervention [29]. They may however be very useful in certain circumstances if done properly by trained hands and carries little morbility [30]. Also, the high aversion for caesarean section in our setting is sufficient reason why obstetricians practicing in developing countries should acquire these skills and apply them when indicated rather than resort to caesarean section in all cases of dystocia in labour [8] [14]. Furthermore, It is believed that for patients of low socio-economic status and poor health seeking behavior who present late in labour with features of obstruction, intra uterine sepsis and fetal death, destructive operation is still a good option that may obviate the need for caesarean section [33] [34].

The reasons for non-use of these procedures were mostly from reasons related to the practitioners and not the patient. Not evidence based (34.62\%), procedures being outdated $(32.60 \%)$ and fears of litigation in the event of complications $(32.7 \%)$ were the three major reasons. Curiously only $(6.52 \%)$ was attributed to decline by patients. Fears of litigation which was reported by $32.7 \%$ of the respondents may be sufficient reason to hesitate in the use of these procedures. A study of American obstetricians showed that $37.1 \%$ of the respondents performed caesarean sections out of fear of litigation [20]. Litigation for medical negligence is rapidly increasing especially in developing countries because people are becoming better educated and aware that in the event of negligence, they can seek and get redress in law courts [35].

The increasing Caesarean section rates may, among other things be attributed to aversion to use of these procedures. Some health institutions report caesarean section rates higher than $10 \%-15 \%$ recommended by the WHO [36]. In developing countries, aversion for caesarean section can push some women with previous caesarean section and poor health seeking behavior to patronize unskilled birth attendants than re-present to the hospital [14] [37]. Ruptured uterus from such patronage has been reported as a major cause of obstetric haemorrhage, maternal and perinatal mortality especially with injudicious use of oxytocic [38] [39] [40].

\section{Conclusion}

In conclusion, there is an urgent need to reverse the declining trend of the use of operative vaginal delivery procedures by re-introducing them into modern obstetric curriculum, especially in resource constrained settings like ours. Capacity building, provision of necessary equipment, more research to provide supportive evidence of need and inclusion in protocols will go a long way in achieving this objective.

\section{References}

[1] Lawani, L.O., Anozie, O.B., Ezeonu, P.O. and Iyoko, C.A. (2014) Comparison of 
Outcomes between Operative Vaginal Deliveries and Spontaneous Vaginal Deliveries in South East, Nigeria. International Journal of Gynaecology and Obstetrics, 125, 206-209. https://doi.org/10.1016/j.ijgo.2013.11.018

[2] Adaji, S.E., Shittu, S.O. and Sule, S.T. (2009) Operative Vaginal Deliveries in Zaria, Nigeria. Annals of African Medicine, 8, 95-99. https://doi.org/10.4103/1596-3519.56236

[3] Shehu, E.C. and Omembelede, J.C. (2016) Instrumental Vaginal Delivery-An Assessment of Use in a Tertiary Care Centre. Orient Journal of Medicine, 28, 23-24.

[4] Sunday-Adeoye, I. and Kalu, C.A. (2011) Pregnant Nigerian Women's View of Caesarean Section. Nigerian Journal of Clinical Practice, 14, 276-279. https://doi.org/10.4103/1119-3077.86766

[5] Betran, A.P., Ye, J., Moller, A., Zhang, J., Gulmezolu, A.M. and Torloni, R. (2016) The Increasing Trend in Caesarean Section Rates: Global, Regional and National Estimates: 1990-2014. PloS ONE, 11, e0148343. https://doi.org/10.1371/journal.pone.0148343

[6] Okeke, T.C. and Ekwuazi, K.E. (2013) Is There Still a Place for Vacuum Extraction (Ventouse) in Modern Obstetric Practice in Nigeria. Annals of Medical and Health Sciences Research, 3, 471-474.

[7] Ekanem, E.I., Udoh, E.A., Agan, T.U. and Ekott, M.I. (2009) Instrumental Vaginal Operative Delivery in University of Calabar Teaching Hospital, Calabar Nigeria. Mary Slessor Journal of Medicine, 9, 23-29.

[8] Onoh, R.C., Ezeonu, P.O., Onoh, T.P., Chijioke, O., Saidu, A.K. and Ezeonu, C.T. (2014) Disappearing Art of Forceps Delivery and the Trend of Instrumental Vaginal Delivery at Abakaliki, Nigeria. African Journal of Medical and Health Sciences, 13, 99-104. https://doi.org/10.4103/2384-5589.144577

[9] Aimakhu, C.O., Olayemi, O., Oladokun, A., Iwe, C.A.B. and Umoh, A.V. (2004) Current Practice of Forceps and Vacuum Deliveries by Nigerian Obstetricians. Tropical Journal of Obstetrics and Gynaecology, 21, 40-43.

[10] Patel, R.R. and Murphy, D.J. (2004) Forceps Delivery in Modern Obstetrics Practice. The BMJ, 328, 1-7. https://doi.org/10.1136/bmj.328.7451.1302

[11] Bofill, J.A., Rust, O.A., Perry, K.G., Roberts, W.E., Martin, R.W. and Morrison, J.C. (1996) Operative Vaginal Delivery: A Survey of Fellows of ACOG. Obstetrics \& Gynecology, 88, 1007-1010. https://doi.org/10.1016/S0029-7844(96)00328-6

[12] Hankins, G.D. and Rowe, T.F. (1996) Operative Vaginal Delivery-Year 2000. American Journal of Obstetrics and Gynecology, 175, 275-281. https://doi.org/10.1016/S0002-9378(96)70135-7

[13] Glen, M. (2010) Operative Vaginal Birth in the 21st Century: A Global Perspective. In: George, A., Tim, D., Alison, G., Dimitrios, S. and Cathy, W., Eds., RCOG Operative Birth Simulation Training: Course, Cambridge, Cambridge University Press.

[14] Ezechi, O.C., Fusubaa, O.B., Kalu, B.E.K., Nwokoro, C.A. and Obesie, L.O. (2004) Caesarean Delivery: Why the Aversion. Tropical Journal of Obstetrics and Gynaecology, 21, 164-167.

[15] Yakasai, I.A., Abubakar, I.S. and Yunus, E.M. (2015) Vacuum Delivery in a Tertiary Institution, in Northern Nigeria: A 5-Year Review. Open Journal of Obstetrics and Gynecology, 5, 213-218. https://doi.org/10.4236/ojog.2015.54031

[16] Martin, J.A., Hamilton, B.E. and Sutton, P.D. (2007) Births: Final Data for 2005. National Vital Statistics Reports, 56, 1-104.

[17] Thomas, J. and Paranjothy, S. (2001) Royal College of Obstetricians and Gynaecol- 
ogists Clinical Effectiveness Support Unit: National Sentinel Caesarean Section Audit Report. Royal College of Obstetricians and Gynecologists Press, London, 1-25.

[18] Katherine, R.G. and George, A.M. (2008) Operative Vaginal Delivery: Current Trends in Obstetrics. Women Health, 4, 281-290. https://doi.org/10.2217/17455057.4.3.281

[19] Shwayder, J. (2007) Liability in High-Risk Obstetrics. Obstetrics \& Gynecology Clinics of North America, 34, 617-625. https://doi.org/10.1016/j.ogc.2007.08.003

[20] Wilson, N. and Strunk, A.L. (2006) Survey on Professional Liability. ACOG Clinical Review, 12, 13-16.

[21] Scottish Programme for Clinical Effectiveness in Reproductive Health (2003) Operative Vaginal Delivery in Scotland a 20 Year Overview. Information \& Statistics Division. Births in Scotland Publication Series, Vol. 4, 1-55.

[22] Martin, J.A., Hamilton, B.E., Ventura, S.J., Osterman, J.K. and Mathews, M.S. (2011) Births: Final Data for 2011. National Vital Statistics Report, 62, 1-70.

[23] Merriam, A.A., Ananth, C.V., Wright, J.D., Siddiq, Z., D’Alton, M.E. and Friedman, A.M. (2017) Trends in Operative Vaginal Delivery, 2005-2013: A Population-Based Study. BJOG, 124, 1365-1372. https://doi.org/10.1111/1471-0528.14553

[24] Anne, W.R., Walter, J.P., Vivienne, P.D. and Fiona, J.S. (1994) Cesarean Section and Operative Vaginal Delivery in Low-Risk Primiparous Women, Western Australia. American Journal of Public Health, 84, 37-43. https://doi.org/10.2105/AJPH.84.1.37

[25] Yannis, S., Eleni, E., Katharii, R., Donald, T. and Dimitrios, T. (1996) Are Operative Delivery Procedures in Greece Socially Conditioned? International Journal for Quality in Health Care, 8, 159-165. https://doi.org/10.1093/intqhc/8.2.159

[26] Royal College of Obstetricians and Gynecologists (2011) Operative Vaginal Delivery. RCOG Green-Top Guideline No. 26, 1-19.

[27] American College of Obstetricians and Gynecologists (2015) ACOG Guidelines at a Glance: Operative Vaginal Delivery. Committee on Practice Bulletins Number 154. Obstetrics \& Gynecology, 126, 56-65. https://doi.org/10.1097/AOG.0000000000001147

[28] Chukwurah, D.C., Eme, O. and Ogbeje, E.M. (2015) Implication of Boko Haram Terrorism on Northern Nigeria. Mediterranean Journal of Social Sciences, 6, 371-380. https://doi.org/10.5901/mjss.2015.v6n3p371

[29] Wykes, C.B., Johnston, J.A., Paterson, S. and Johanson, R.B. (2003) Symphysiotomy: A Life Saving Procedure. BJOG, 110, 219-221. https://doi.org/10.1046/j.1471-0528.2003.02001.x

[30] Maharaj, D. and Moodly, J. (2002) Symphysiotomy and Fetal Destructive Operation. Best Practice \& Research: Clinical Obstetrics \& Gynaecology, 16, 117-125.

[31] Abegizer, A., Feyissa, T.G. and Gurmessa, A. (2015) Operative Deliveries: Indications and Postoperative Complications at Mattu Karl Hospital, Oromia Regional State, Southwest Ethiopia. Journal of Health, Medicine and Nursing, 16, 42-46.

[32] Kadas, A.S., Aliyu, L.D. and Hauwa, M.A. (2011) Instrumental Vaginal Delivery in Bauchi, North-East Nigeria. Journal of the West African College of Surgeons, 1, 18-27.

[33] Singhal, S.R., Chaudhry, P., Sangwan, K. and Singhal, S.K. (2005) Destructive Operations in Modern Obstetrics. Archives of Gynecology and Obstetrics, 273, 107-109. https://doi.org/10.1007/s00404-005-0042-x

[34] Gupta, U. and Chitra, R. (1994) Destructive Operations Still Have a Place in Developing Countries. International Journal of Gynecology \& Obstetrics, 44, 15-19. 
https://doi.org/10.1016/0020-7292(94)90017-5

[35] Chukwuneke, F.N. (2015) Medical Incidents in Developing Countries: A Few Case Studies from Nigeria. Medical Incidents in Developing Countries: A Few Case Studies from Nigeria. Nigerian Journal of Clinical Practice, 18, S20-S24. https://doi.org/10.4103/1119-3077.170821

[36] Betran, A.P., Torloni, M.R., Zhang, J.J. and Gülmezoglu, A.M. (2016) WHO Working Group on Caesarean Section. BJOG, 123, 667-670. https://doi.org/10.1111/1471-0528.13526

[37] Obuna, J.A., Ugboma, H.A., Ejikeme, B.N., Umeora, O.U. and Agwu, U.M. (2012) Pattern and Outcome of Higher Order Caesarean Section in a Secondary Health Facility in Nigeria. Research in Obstetrics \& Gynecology, 1, 19-22.

[38] Eze, J.N. (2010) Uterine Rupture at a Secondary Hospital in Afikpo, Southeast Nigeria. Singapore Medical Journal, 51, 506-511.

[39] Ezegwui, H.U., Onoh, R.C., Ikeako, L.C., Onyebuchi, A., Umeora, J. and Ibekwe, P. (2013) Investigating Maternal Mortality in a Public Teaching Hospital, Abakaliki, Ebonyi State, Nigeria. Annals of Medical and Health Sciences Research, 3, 75-81. https://doi.org/10.4103/2141-9248.109511

[40] Mbamara, S.U., Obiechina, N.J.A. and Eleje, G.U. (2012) An Analyisis of Uterine Rupture at the Nnamdi Azikiwe University Teaching Hospital Nnewi, Southeast Nigeria. Nigerian Journal of Clinical Practice, 15, 448-453.

https://doi.org/10.4103/1119-3077.104524 